\title{
The Indolic Compound Hypaphorine Produced by Ectomycorrhizal Fungus Interferes with Auxin Action and Evokes Early Responses in Nonhost Arabidopsis thaliana
}

\author{
David Reboutier, ${ }^{1}$ Michele Bianchi, ${ }^{2}$ Mathias Brault, ${ }^{1}$ Camille Roux, ${ }^{2}$ Aurélien Dauphin, ${ }^{1,3}$ Jean-Pierre \\ Rona, ${ }^{1}$ Valérie Legué, ${ }^{3}$ Frédéric Lapeyrie, ${ }^{3}$ and François Bouteau ${ }^{1}$ \\ ${ }^{1}$ Laboratoire d'Electrophysiologie des Membranes (LEM) EA 3514, Université Denis Diderot - Paris 7, Case 7069, 2 place \\ Jussieu, F-75251 Paris Cedex 05, France; ${ }^{2}$ Laboratoire de Biologie Cellulaire et Moléculaire de l'Adaptation à la \\ Sécheresse (BMAS), Université Paris XII - Val de Marne, 61 Avenue du Général de Gaulle F-94010 Créteil Cedex, France; \\ ${ }^{3}$ Unité Mixte de Recherche UMR INRA-UHP Interactions Arbres/Microorganismes, F-54 280 Champenoux, France \\ Submitted 4 December 2001. Accepted 22 April 2002.
}

Signals leading to mycorrhizal differentiation are largely unknown. We have studied the sensitivity of the root system from plant model Arabidopsis thaliana to hypaphorine, the major indolic compound isolated from the basidiomycetous fungus Pisolithus tinctorius. This fungi establishes ectomycorrhizas with Eucalyptus globulus. Hypaphorine controls root hair elongation and counteracts the activity of indole-3-acetic acid on root elongation on $A$. thaliana, as previously reported for the host plant. In addition, we show that hypaphorine counteracts the rapid upregulation by indole-3-acetic acid and 1-naphthalenic-acetic acid of the primary auxin-responsive gene $I A A I$ and induces a rapid, transient membrane depolarization in root hairs and suspension cells, due to the modulation of anion and $\mathrm{K}^{+}$currents. These early responses indicate that components necessary for symbiosis-related differentiation events are present in the nonhost plant $A$. thaliana and provide tools for the dissection of the hypaphorine-auxin interaction.

Additional keyword: Ion channels.

Mycorrhizas are symbiotic associations between roots of most land plants and soil fungi. The establishment of mycorrhiza is accompanied by important morphogenetic events such as, on the plant's side, reduction of tap root growth and stimulation of lateral root formation, shape modifications of root epidermal cells, and inhibition of root hair elongation (Barker et al. 1998; Martin et al. 1997). Changes in the distribution of phytohormones, especially auxin, which is also synthesized by many ectomycorrhizal fungi, underlie these differentiation events (Barker and Tagu 2000; Beyrle 1995; Gay et al. 1994; Gogala 1991; Kaldorf and Ludwig-Müller, 2000; Laurans et al. 2001). However, the early signals produced by the symbionts to initiate mycorrhizas and evoke the accompanying changes in gene expression (Martin et al. 1997) are still largely unknown (Hahn and Mendgen 2001).

Corresponding author: François Bouteau; E-mail: bouteau@ccr.jussieu.fr.

This article is in the public domain and not copyrightable. It may be freely reprinted with customary crediting of the source. The American Phytopathological Society, 2002.
During the establishment of the mycorrhiza between $\mathrm{Pi}$ solithus tinctorius and Eucalyptus globulus, the mycelium accumulates and exudes the indole alkaloid hypaphorine or betaine tryptophan (Béguiristain et al. 1995). This molecule is the first identified fungal molecule that induces symbiosis-related differentiation (Béguiristain and Lapeyrie 1997). Hypaphorine reduced elongation of root hairs (Béguiristain and Lapeyrie 1997); this effect being reverted by an exogenous indole-3-acetic acid (IAA) application (Ditengou et al. 2000). Hypaphorine counteracted the activity of the natural auxin IAA on root elongation but did not affect the activity of the synthetic auxins, 2,4-dichlorophenoxy-acetic acid (2,4-D) and 1-naphthalenicacetic acid (NAA) (Ditengou and Lapeyrie 2000). Hypaphorine also up-regulated RNA levels of the glutathione-S-transferase encoded by EgHypar, a plant symbiosis-related gene (Nehls et al. 1998). Thus, the possibility exists that hypaphorine, through its interaction with endogenous auxin, serves as a trigger for mycorrhization, just as Nod factor is considered the primary morphogenetic signal in nitrogen-fixing nodule symbioses.

Although Arabidopsis thaliana, as any of the family Brassicaceae, has never been reported to develop mycorrhizas or nitrogen-fixing nodules, this nonlegume dicot was successfully tested to study the early interaction with diazotrophic bacteria (Gough et al. 1997). In the case of mycorrhizas, it was postulated that genes involved in this process would be present in all land plants, whether or not they actually form mycorrhizas, because of the very ancient origin of this symbiosis (Barker et al. 1998). Thus, we make the hypothesis that plant model $A$. thaliana could respond to the fungal molecule hypaphorine. The results presented here are consistent with this hypothesis: hypaphorine has similar effects on A. thaliana, a nonhost plant, as compared with E. globulus. Further data presented here show that hypaphorine interferes with auxin-dependent gene expression and that components of a signaling pathway possibly initiating mycorrhization are present in A. thaliana.

\section{RESULTS}

Effect of hypaphorine on root length.

To determine whether $A$. thaliana roots respond to hypaphorine similarly to the response observed in E. globulus, A. thaliana seedlings were grown for 4 days on solid medium containing different concentrations of hypaphorine, and root 
lengths were scored. Whatever the concentrations used, hypaphorine did not affect root elongation (Fig. 1A). Even at 750 $\mu \mathrm{M}$, hypaphorine had no effect on the root length (data not shown). Conversely, the addition of IAA in the nutrient medium resulted in a dose-dependent inhibition of root elongation (Fig. 1A). However, seedlings grown in the presence of both IAA and hypaphorine presented a less pronounced auxin-induced root-growth inhibition (Fig. 1A). Therefore, hypaphorine is able to counteract the inhibitory effect of IAA on root elongation in A. thaliana root. Similar experiments were performed with synthetic auxins. Conversely, the inhibition of root elongation induced by synthetic auxins 2,4-D and NAA was not counteracted by hypaphorine (Fig. 1B and C). As previously suggested for E. globulus (Ditengou and Lapeyrie 2000), the fact that both nonindolic auxins are not antagonized by hypaphorine could imply that there are two different receptors for indolic and nonindolic compounds.

\section{Effect of hypaphorine on root hair length.}

Hypaphorine reduced the length of root hairs from zone I according to Heidstra and associates (1994) (Fig. 2A and B). This inhibitory effect was dose dependent and effective for concentrations above $1 \mu \mathrm{M}$, with the maximal effect of hypaphorine on root hair elongation being reached at $100 \mu \mathrm{M}$ (Fig. 2C). On the other hand, addition of IAA in the medium increased root hair length in a dose-dependent manner (Fig. 2D). Root hairs of seedlings grown on solid medium containing a combination of IAA and hypaphorine were shorter than those grown in the presence of IAA alone. This was observed whatever the IAA concentration used (Fig. 2D). As established for root elongation, hypaphorine can also counteract the effect of IAA on elongation of root hair in A. thaliana.

To study the short-term effect of hypaphorine on growth rate, the elongation of root hairs in 4-day-old plantlets grown on buffer solution (BS) was monitored for $2 \mathrm{~h}$. Over this period and in the absence of hypaphorine, growth rate was constant (Fig. 3A). The addition of hypaphorine, at a concentration inhibiting root hair elongation $(200 \mu \mathrm{M})$, dramatically reduced the root hair growth rate within 40 minutes (Fig. 3A and B) and induced tip swelling in some root hairs, indicating apical growth inhibition (Fig. 3B, inset). However, the growth rate of hypaphorine-treated root hairs could be restored upon addition of $1 \mu \mathrm{M}$ IAA in the medium (Fig. 3B). Hypaphorine is therefore able to rapidly control the growth of A. thaliana root hairs.
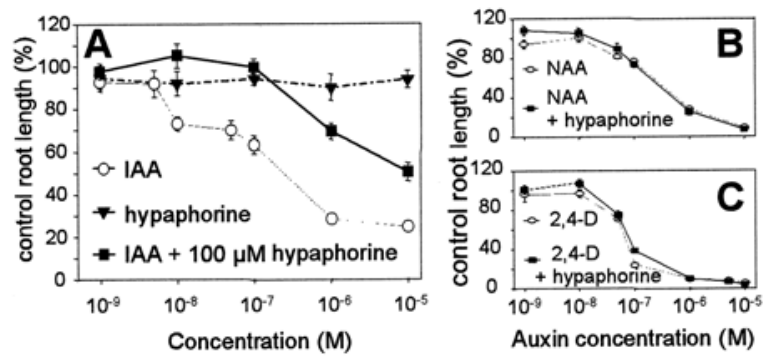

Fig. 1. Effect of hypaphorine and auxins on root length. A, Root lengths of 4-day-old Arabidopsis thaliana seedlings cultivated over agar containing buffer solution (BS) (control) supplemented with $10^{-9}$ to $10^{-5} \mathrm{M}$ hypaphorine $(\boldsymbol{\nabla}), 10^{-9}$ to $10^{-5} \mathrm{M}$ indole-3-acetic acid (IAA) alone (O) or in combination with $100 \mu \mathrm{M}$ hypaphorine (ם). B, Root lengths of seedlings cultivated over BS supplemented with $10^{-9}$ to $10^{-5} \mathrm{M} 1$ naphthalenic-acetic acid (NAA) alone (O) or in combination with 100 $\mu \mathrm{M}$ hypaphorine (ם). C, Root lengths of seedlings cultivated over BS supplemented with $10^{-9}$ to $10^{-5}$ M 2-4,D alone(O) or in combination with $100 \mu \mathrm{M}$ hypaphorine ( $\mathbf{\square})$. Mean values were recorded from at least 12 seedlings \pm SE. $100 \%$ represents the control root length.
The inhibitory concentration of hypaphorine applied could appear too high to be specific. However, as previously discussed (Ditengou et al. 2000; Ditengou and Lapeyrie 2000; Nehls et al. 1998), this concentration is not unrealistic; hypaphorine is the most abundant indolic compound present in colonizing hyphae, with its concentration (up to $6 \mathrm{mM}$ ) being 1,000 times higher than the IAA concentration in $P$. tinctorius strain 441 (Bégueristain et al. 1995).

\section{Effect of hypaphorine}

on $I A A 1$ and $A t G S T 8$ transcript accumulation.

The hypaphorine-auxin interaction was also tested at the gene expression level by following the accumulation of IAAI and $G S T 8$ transcripts in A. thaliana roots. IAAl is a primary auxin-responsive gene, shown to be specifically and rapidly induced by IAA, NAA, and 2,4-D in etiolated seedlings (Abel et al. 1994). GST8 (GenBank AJ012571; Bianchi et al. 2002) encodes an A. thaliana glutathione-S-transferase homologous to the E. globulus symbiosis-related enzyme EgHypar, sharing 63.6\% identities over 217 residues. EgHypar transcripts were shown to accumulate in E. globulus roots after long-term incubations (4 days) in the presence of hypaphorine as well as IAA (2 days) (Nehls et al. 1998), while AtGST8 transcripts are up-regulated by high doses of auxins $(100 \mu \mathrm{M})$ and oxidative stress (Bianchi et al. 2002).

The antagonism of hypaphorine with IAA or with the synthetic auxin NAA was examined in 7-day-old seedlings after 1$\mathrm{h}$ and 16-h incubations. IAAl RNA accumulation was efficiently induced at similar levels by $10 \mu \mathrm{M}$ concentrations of the two auxins. However, when hypaphorine $(100 \mu \mathrm{M})$ was also present, induction factors were significantly weaker $(60 \%)$ at both incubation times. In these conditions, GST8 transcript accumulation was stimulated only by NAA, transiently and independently of hypaphorine (Fig. 4A).

The hypaphorine dose response was then investigated after a 1 -hour incubation in the presence of or the absence of $10 \mu \mathrm{M}$ IAA. Concentrations of hypaphorine, starting from $10 \mu \mathrm{M}$, antagonized auxin-induced accumulation of IAAI transcripts, while hypaphorine alone did not affect IAAI RNA levels. The abundance of AtGST8 transcripts increased only at the highest hypaphorine concentration tested $(750 \mu \mathrm{M})$ (Fig. 4B).
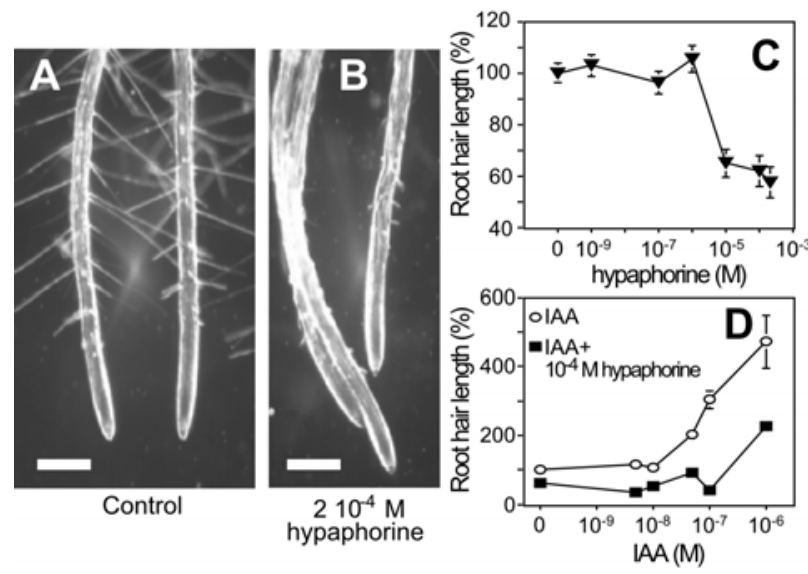

Fig. 2. Long-term effect of hypaphorine and indole-3-acetic acid (IAA) on root hair length. A, Root tips of 4-day-old Arabidopsis thaliana seedlings cultivated over buffer solution (BS). B, Root tips of seedlings cultivated over BS supplemented with $200 \mu \mathrm{M}$ hypaphorine. White bars = $300 \mu \mathrm{m}$. C, Root-hair lengths measured on the first millimeter of the root tip of seedlings cultivated over BS supplemented with increasing hypaphorine concentrations D, Root-hair lengths measured on the first millimeter of the root tip of seedlings cultivated over BS for control or BS supplemented with $10^{-9}$ to $10^{-6} \mathrm{M}$ IAA alone $(\mathrm{O})$ or in combination with $100 \mu \mathrm{M}$ hypaphorine (ם). Mean values were recorded for at least 12 seedlings $\pm \mathrm{SE}$. 
Effect of hypaphorine on root hair membrane potential.

Modulations of ionic currents across the plasma membrane are among the earliest events in plant-microbe interactions. In order to assess whether hypaphorine could modulate ionic currents, an electrophysiological study was undertaken. The value of the resting membrane potential $\left(\mathrm{V}_{\mathrm{m}}\right)$, using BS, was $-123 \pm$ $15 \mathrm{mV}(n=24)$ of the same order of magnitude as those recorded on root hairs from various species (Bouteau et al. 1999, Dauphin et al. 2001). A typical example of the $V_{m}$ recording of a root hair from a 4-day-old plantlet treated with $200 \mu \mathrm{M}$ hypaphorine is shown in Figure 5. Hypaphorine induces a rapid transient depolarization with a mean amplitude of $+38 \pm 11 \mathrm{mV}$ (mean $\pm \mathrm{SD}, n=6$ ). The membrane repolarized in the presence of hypaphorine (Fig. 5). When root hairs were treated successively with the same hypaphorine concentration, the depolarization became nil (not shown), indicating a decrease in the reactivity of root hairs to hypaphorine.

\section{Effect of hypaphorine}

\section{on suspension cell membrane potential and currents.}

To characterize the ionic currents underlying the observed plasma membrane depolarization, we used A. thaliana suspension cells (Axelos et al. 1992) as the simplest experimental model. Previous studies (El-Maarouf et al. 2001; Ghellis et al. 2000; Jeannette et al. 1999) had identified two ion channel currents in the plasma membrane of $A$. thaliana cultured cells. Based on these currents, three populations could be discriminated.

The first population $(60 \%)$ displayed predominant currents that were previously described as slow-type anion channels (SLAC) that were responsible for anion fluxes (El-Maarouf et al. 2001; Ghellis et al. 2000). They showed the slow activation and deactivation (Fig. 6A) of SLAC (Schroeder and Keller 1992), although some of the instantaneous currents could be carried by fast-activating anion channels, as described for guard cells (Hedrich et al. 1990). Since long hyperpolarizing voltages could modify the ionic cell content, we also recorded the signature of this current under shorter protocol. A typical signature of SLAC current under short protocol is shown in the right part of Figure 6A. These currents were sensitive to $40 \mu \mathrm{M}$ niflumic acid (Fig. 6B) and 9-anthracene carboxylic acid (9AC; data not shown), two potent anion channel blockers. These
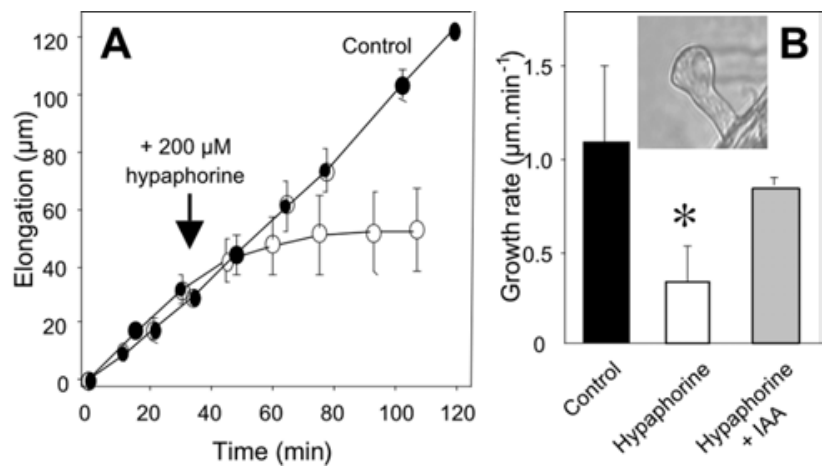

Fig. 3. Short-term effect of hypaphorine on root hair growth. A, Hairs from control roots were incubated in buffer solution (BS) ( For hypaphorine treatment, $200 \mu \mathrm{M}$ hypaphorine was added after $30 \mathrm{~min}$ (O). B, Growth rate of the control root hairs (black bar) was compared with the growth rate of root hairs 20 min after treatment with $200 \mu \mathrm{M}$ hypaphorine (white bar). Inset: swelling of the root hair tip during the decrease of the growth. After $20 \mathrm{~min}$ of treatment with $200 \mu \mathrm{M}$ hypaphorine, the addition of $1 \mu \mathrm{M}$ IAA in the medium restores the growth rate in about 20 min (gray bar). Mean values recorded for at least six root hairs from at least four seedlings $\pm \mathrm{SD}$. *, Significantly different from the control growth rate $(P<0.05 \%)$. cells with predominant SLAC currents had a plasma membrane potential of $-27 \pm 12 \mathrm{mV}(n=52)$, thus close to the equilibrium potential estimated for $\mathrm{NO}_{3}^{-}\left(\mathrm{E}_{\mathrm{NO} 3}{ }^{-} \approx-20 \mathrm{mV},\left[\mathrm{NO}_{3}{ }^{-}\right]_{\text {out }}\right.$ $=11 \mathrm{mM}$ with $\left[\mathrm{NO}_{3}^{-}\right]_{\text {in }}$ estimated at $5 \mathrm{mM}$ ). Taking all these data together, the slow anion channels are good candidates for the mediation of these large deactivating currents.

The second cell population (7\% of the cells) presented predominant time- and voltage-dependent outward rectifying currents activated by depolarizing pulses (Fig. 7A). These currents were previously characterized as $\mathrm{KORC}$ for $\mathrm{K}^{+}$outward rectifying currents (El-Maarouf et al. 2001; Jeannette et al. 1999). They are due to $\mathrm{K}^{+}$efflux. These currents are sensitive to the potassium channel blocker $\mathrm{Ba}^{2+}$ at $10 \mathrm{mM}$ (Fig. 7A) but insensitive to 9-AC, even at $80 \mu \mathrm{M}$ (not shown). These cells with predominant KORC were polarized at $-59 \pm 17 \mathrm{mV}(n=7)$ and, thus, were closed to the equilibrium potential estimated for $\mathrm{K}^{+}$in our conditions $\left(\mathrm{E}_{\mathrm{K}}+\approx-60 \mathrm{mV},\left[\mathrm{K}^{+}\right]_{\text {out }}=9 \mathrm{mM}\right.$ with $\left[\mathrm{K}^{+}\right]_{\text {in }}$ estimated at $\left.100 \mathrm{mM}\right)$. The third population (32\%) corresponds to cells having mixed KORC and SLAC currents. These cells were polarized at $-45 \pm 29 \mathrm{mV}(n=28)$, namely between the estimated equilibrium potential of $\mathrm{K}^{+}$and that of $\mathrm{NO}_{3}^{-}$.

As observed with root hairs, hypaphorine induced a depolarization, detected in $60 \%$ of the 26 tested cells whatever their polarizations (Figs. 6C, 7B). The mean amplitude of the depolarization induced by $200 \mu \mathrm{M}$ hypaphorine was $-10 \pm 5 \mathrm{mV}(n$ $=16)$, and was reached in $2.5 \pm 1 \mathrm{~min}(n=13)$. The membrane repolarized in the presence of hypaphorine (Figs. 6C, 7B), the amplitude of repolarization being $-9 \pm 5 \mathrm{mV}(n=13)$, attained in $5.3 \pm 3 \min (n=13)$.

Upon the addition of $200 \mu \mathrm{M}$ hypaphorine to cells displaying SLAC, an increase of the anion currents was observed during depolarization (Fig. 6C). Repolarization was accompanied by a decrease of these currents down to levels similar to those measured before hypaphorine addition (Fig. 6C). In cultured cells showing KORC, hypaphorine treatment decreased $\mathrm{K}^{+}$efflux through KORC during the depolarization, the initial current intensity being recovered during repolarization (Fig. 7B).

On E. globulus, the hypaphorine activity cannot be mimicked by betaine (Béguiristain and Lapeyrie 1997). Tryptophan, the second constitutive element of the hypaphorine molecule, could mimic to a lesser extent some effects of hypaphorine (Ditengou and Lapeyrie 2000). Thus, we checked the effect of $200 \mu \mathrm{M}$ tryptophan on A. thaliana suspension cells. The mean effect on polarization was $-2 \pm 1.6 \mathrm{mV}(n=4)$ in $4 \mathrm{~min}$, and no significant effect was observed on ion currents. We also wanted to check the effect of IAA, known as a potent regulator of ion channels (Blatt and Thiel 1993, Marten et al. 1991, Zimmermann et al. 1994), on cell polarization and ion currents. Unfortunately, no reproducible recordings could be obtained for the concentrations of IAA we used $\left(10^{-7} \mathrm{M}\right.$ to $10^{-4} \mathrm{M}$ ). Moreover, upon addition of IAA (data not shown), the $\mathrm{pH}$ time course of the cell external medium did not reveal the $\mathrm{H}^{+}$pump stimulation previously described for various plant cells (Bates and Goldsmith 1983; Brummer et al. 1984; Cleland et al 1977; Santoni et al. 1990; Rück et al. 1993; Yuasa et al. 1998).

\section{DISCUSSION}

Mycorrhizal symbiosis is a central feature of a large number of plants, conditioning their development and growth. However, early steps occurring during the symbiosis installation are largely unknown (Hahn and Mendgen 2001). Hypaphorine is the major indolic compound isolated from the ectomycorrhizal fungus $P$. tinctorius (Béguiristain et al. 1995). This molecule induces early differentiation events mimicking the effect of the 
ectomicorrhizal fungus on the host plant E. globulus (Béguiristain and Lapeyrie 1997; Ditengou and Lapeyrie 2000; Ditengou et al. 2000; Nehls et al. 1998).

We demonstrated that: (i) hypaphorine had no effect on root elongation but (ii) was able to counteract the IAA-induced inhibition of root elongation; (iii) hypaphorine reduced root hair length rapidly, since the typical swelling of root hair tips indicating tip growth arrest was observed within a few minutes; (iv) the inhibition of root hair growth was reverted by exogenous IAA; and (v) hypaphorine $(750 \mu \mathrm{M})$ led to an increase in mRNA levels of AtGST8, a putative homolog of the symbiosis-related gene EgHypar. These observations, which are similar to those described in E. globulus, suggest that components required for the plant response to hypaphorine are present in A. thaliana.

The availability of well-characterized and highly specific hormone responsive genes in $A$. thaliana allowed us to show that hypaphorine interferes with early auxin signaling by following
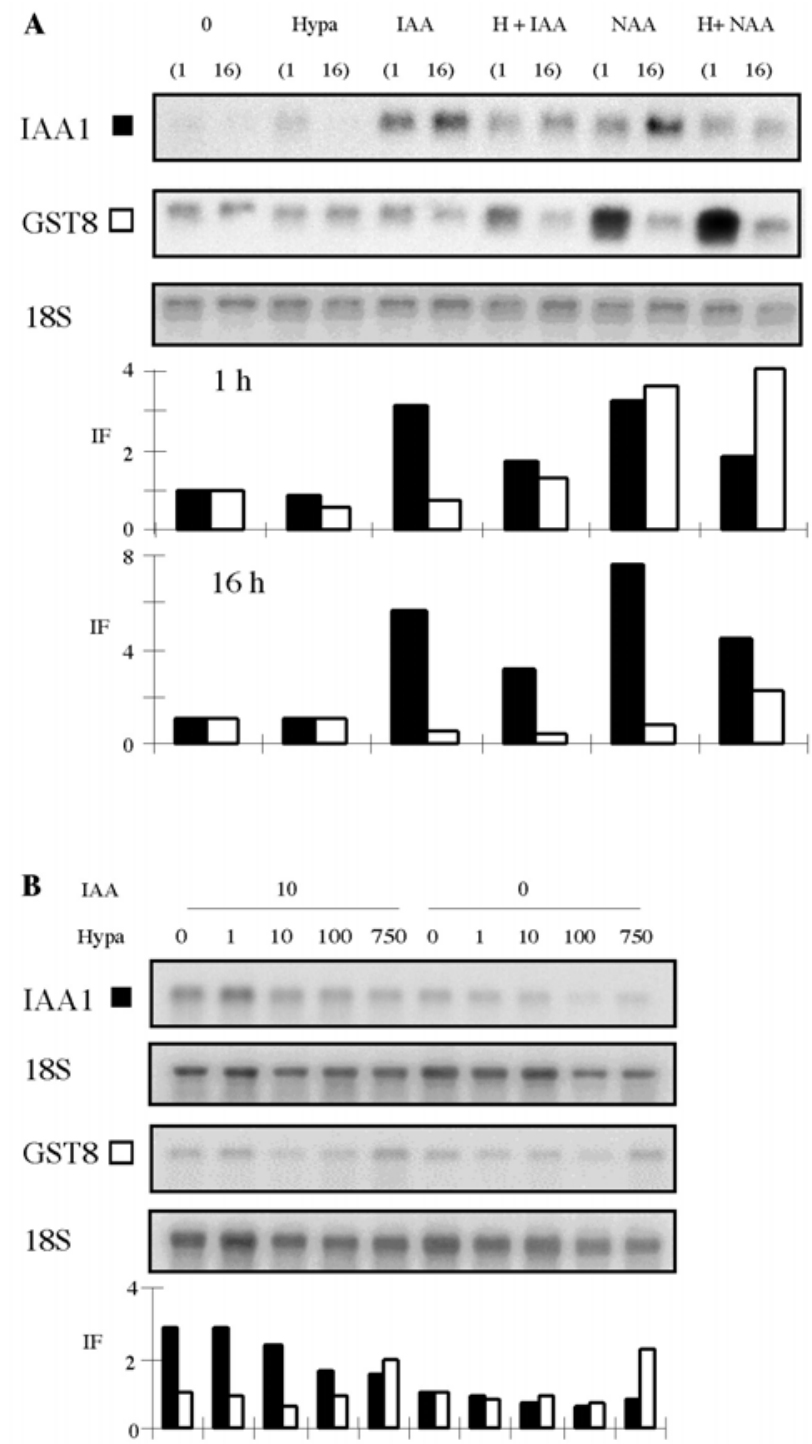

Fig. 4. Hypaphorine effect on IAAI and GST8 mRNA levels. A, Treatments of 7-day-old Arabidopsis thaliana seedlings with either $100 \mu \mathrm{M}$ hypaphorine in the presence of or the absence of auxins [10 $\mu \mathrm{M}$ indole-3acetic acid (IAA) or $10 \mu \mathrm{M}$ 1-naphthalenic-acetic acid]. Incubation times are indicated. B, Hypaphorine dose response $(0$ to $750 \mu \mathrm{M})$ in the absence of or the presence of $10 \mu \mathrm{M}$ IAA. Incubation time was $1 \mathrm{~h}$. Control hybridizations with an 18S rRNA probe are presented under the corresponding blot. Histograms represent induction factors over levels in

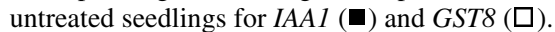

IAAl transcript accumulation, which is induced rapidly by auxins and independently of protein synthesis (Abel et al. 1994). Hypaphorine alone did not appear to affect IAAl RNA levels but counteracted their upregulation in the presence of exogenous IAA and NAA (Fig 4). Our results therefore indicate for the first time that this compound can counteract auxin action, not only in cell-elongation control but also at the gene expression level. It is interesting to note that hypaphorine also antagonized the effect of the synthetic, nonindolic auxin NAA on IAAl RNA levels (Fig. $4 \mathrm{~A}$ ), in contrast to observations based on cell elongation rates, which suggested a specificity for IAA (this study; Ditengou and Lapeyrie 2000). In E. globulus, hypaphorine was shown to induce expression of the symbiosis-related EgHypar gene, whose RNA levels increased in seedlings incubated with either $10 \mu \mathrm{M}$ hypaphorine (for 4 days) or with $10 \mu \mathrm{M}$ IAA (for 2 days) (Nehls et al. 1998). These observations led to the apparent paradox of an auxin responsive gene being up-regulated by both an auxin (IAA) and an auxin antagonist (hypaphorine) as discussed by Ditengou and Lapeyrie (2000). In the present study, hypaphorine concentrations capable of rapidly countering the regulation by auxin of IAAI transcript accumulation or of cell elongation did not, however, affect RNA levels of AtGST8, which were up-regulated after 1-h incubations only by higher doses of the compound $(750 \mu \mathrm{M})($ Fig. 4B). Furthermore, in contrast with IAA1, GST8 RNA levels were increased in short-term experiments only by very high doses of IAA (50 or $100 \mu \mathrm{M}$, data not shown), or, but only transiently and independently of hypaphorine, by $10 \mu \mathrm{M}$ NAA. A hypaphorine-mediated inhibition of auxin action is, therefore, unlikely to be responsible for GST8 induction. High doses of hypaphorine and auxins may act independently of canonical auxin signaling pathways to control GST8 transcripts levels, possibly by causing chemical and oxidative stresses, which are known inducers of glutathione-S-transferase expression (Marrs 1996; Edwards et al. 2000).

As a whole, our results support the hypothesis that hypaphorine plays a role as a competitor of auxin activity in the regulation of symbiosis-associated differentiation (Ditengou and Lapeyrie 2000). Unfortunately, analysis of the competition between IAA and hypaphorine at the ionic current level could not be performed. Even with a subculture of suspension cells on Gamborg medium free from auxin, no reliable response to auxin was obtained. Previous studies have shown that auxin could regulate ion transport systems in plant cells. The electrical response of various plant cells to IAA looks like the response to hypaphorine; it consists of an immediate depolarization followed by a repolarization (Bates and Goldsmith 1983; Cleland et al 1977; Felle et al. 1986, 1991; Keller and Volkenburgh 1996; Tretyn et al. 1991). The stimulation of anion currents was suggested to initiate the initial depolarization (Keller and Volkenburgh 1996), thus resembling the hypaphorine response. However, fine data concerning anion channel regulation by auxin remained scarce. Auxin does not strictly activate rapid-type anion channels, but rather, modulates their voltage-dependent regulation in a way that facili-

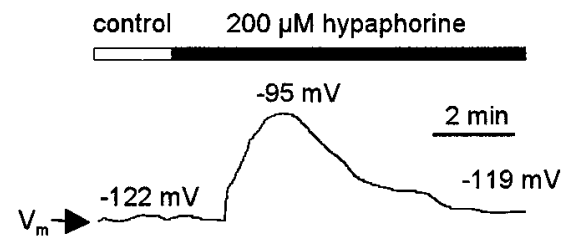

Fig. 5. Hypaphorine-induced changes in root hair membrane potential. Typical recording of the membrane potential $\left(\mathrm{V}_{\mathrm{m}}\right)$ of a young root hair in buffer solution. The bar illustrates the time when $200 \mu \mathrm{M}$ hypaphorine was added to the bath solution. 
tates their activation by a small depolarization (Marten et al. 1991, Zimmermann et al. 1994). No data concerning SLAC is available to our knowledge. During depolarization, hypaphorine reduced the KORC (Fig. 7B), contrary to what was observed with IAA and NAA, which evoked a rapid (1 to $3 \mathrm{~min}$ ) rise of KORC on guard cells (Blatt and Thiel 1993), a hyperpolarizing mechanism. However, auxin-induced hyperpolarization was mainly attributable to plasma membrane $\mathrm{H}^{+}$-ATPases stimulation (Bates and Goldsmith 1983; Brummer et al. 1984; Cleland et al 1977; Rück et al. 1993; Santoni et al. 1990; Yuasa et al. 1998), although it is not clear in all situations (Keller and Volkenburgh 1998). Nevertheless, hypaphorine failed to activate the $\mathrm{H}^{+}$pump (data not shown), although suspension cells did not always respond to auxins in the same way they responded in planta in Zea mays cells (Felle et al. 1991).

However, the early plasma membrane depolarization and root hair growth inhibition induced by hypaphorine could suggest a role for this molecule in the chemical dialogs between both symbionts during the precontact phase. Interestingly, the early hypaphorine-induced depolarization was transient, and a desensitization of the root hair to the symbiosis factor was observed, resembling the well-known depolarization induced by Nod factor (Ehrhardt et al. 1992; Felle et al. 1998; Kurkdjian

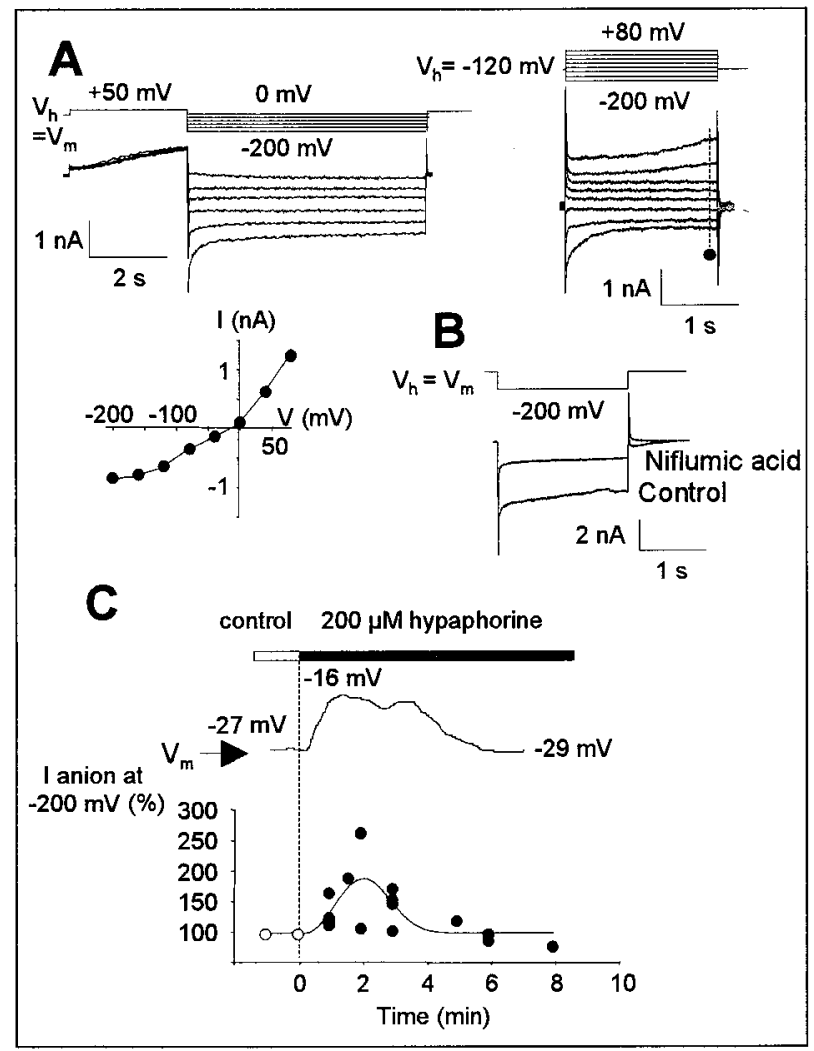

Fig. 6. Hypaphorine-induced changes in slow-type anion currents (SLAC) of suspension cells. A., Slow activation of SLAC in response to a depolarizing voltage step of $+50 \mathrm{mV}$. At the end of the voltage pulse, the membrane potential was repolarized to voltage steps from -200 to 0 $\mathrm{mV}$, which resulted in large slow relaxation currents. Currents recorded with a shorter time protocol on the same cell and corresponding currentvoltage curve. B, Currents measured in control conditions and in the presence of $40 \mu \mathrm{M}$ niflumic acid, an anion channel inhibitor $\left(\mathrm{V}_{\mathrm{h}}=\right.$ holding potential, $\mathrm{V}_{\mathrm{m}}=$ membrane potential). $C$. Typical recording of the $\mathrm{V}_{\mathrm{m}}$ of a suspension cultured cell in Gamborg medium. Time course of SLAC at $-200 \mathrm{mV}$ and after $1.9 \mathrm{~s}$ of deactivation in response to the addition of hypaphorine. Data obtained from six independent cells (black points) were fitted by a 5 -parameter Weibull equation (solid line).
1995), the primary morphogenetic signal in nitrogen-fixing nodule symbiosis (Cullimore et al. 2001; Dénarié and Cullimore 1993). Furthermore, the regulation of the potassic and anionic currents explaining the hypaphorine-induced depolarization resembles the hypothetical models proposed for the Nod-factor signaling pathway, which involve a transient increase of anion efflux and transient regulation of potassium fluxes (Felle et al. 1998, Kurkdjian et al. 2000). This could be correlated to the hypothesis of a conservation of signal transduction pathways between the two symbioses formulated by van Rhijn and associates (1997). On the contrary, this ion flux regulation is clearly different from the events we recently described in A. thaliana suspension cells in response to harpin, a bacterial hypersensitive response elicitor (El-Maarouf et al. 2001), indicating that symbiont and pathogen signals are clearly discriminated in this experimental system. It was recently reported that an ionophore-induced depolarization could be sufficient to regulate gene expression (Schaller and Frasson 2001). Similarly, the depolarization induced by the stimulation of anion channel activity in response to abscisic acid is necessary to regulate expression of the $R A B 18$ gene (Ghellis et al. 2000). Thus, the hypaphorine-induced depolarization might constitute an early step in a signal transduction pathway, to some extent conserved between A. thaliana and E. globulus, controlling the plant response to this compound.

In conclusion, we described early developmental, molecular, and electrophysiological responses of $A$. thaliana roots and cells to the indolic compound hypaphorine produced by ectomycorrhizal fungus Pisolithus tinctorius. Future studies should

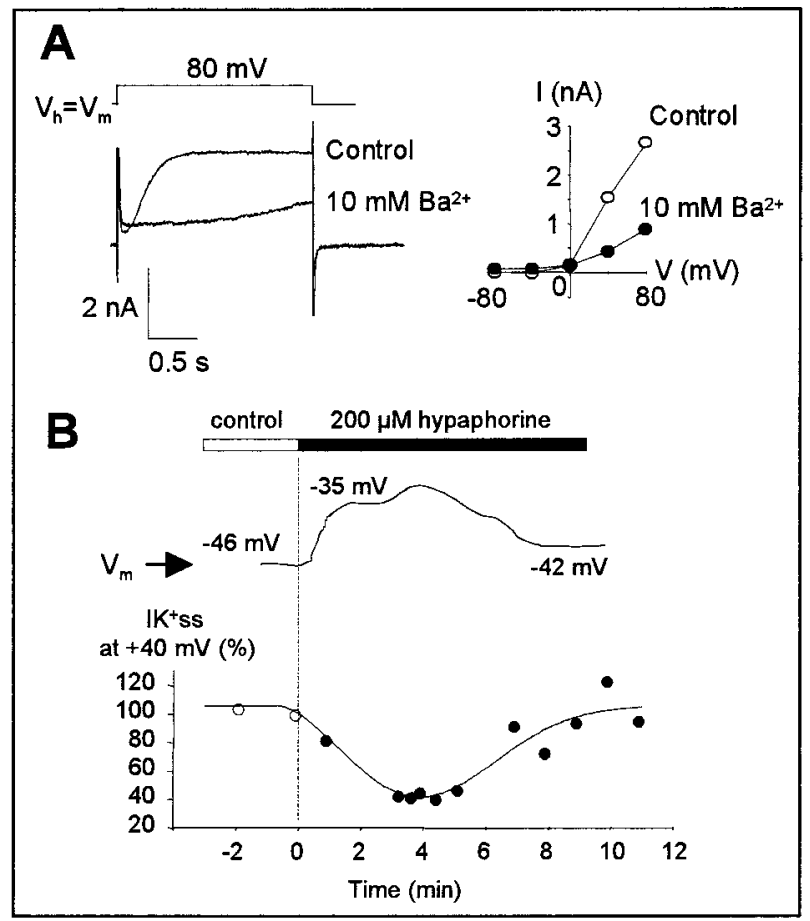

Fig. 7. Hypaphorine induced changes in potassium currents of suspension cells. A, The time-dependent $\mathrm{K}^{+}$outward rectifying currents (KORC) at $+80 \mathrm{mV}$ (leak subtracted) were measured in control conditions and after addition of $10 \mathrm{mM} \mathrm{BaCl}_{2}$, a $\mathrm{K}+$ channel inhibitor. Current-voltage curves corresponding to the whole voltage domain tested. B, Typical recording of the root hair membrane potential $\left(\mathrm{V}_{\mathrm{m}}\right)$ of a suspension cultured cell in Gamborg medium. The bar illustrates the time when hypaphorine $(200 \mu \mathrm{M})$ was added to the bath solution. Time course of KORC after hypaphorine addition. The current values correspond to steady state currents (Iss) recorded at $+80 \mathrm{mV}$. Data obtained from six independent cells (black points) were fitted by a 5-parameter Weibull equation (solid line). 
take advantage of these tools and of $A$. thaliana genetics to dissect the auxin/hypaphorine interaction, yielding useful information for the evaluation of hypaphorine's role in the establishment of ectomycorrhizas.

\section{MATERIALS AND METHODS}

\section{Chemicals.}

Hypaphorine was chemically synthesized (Romburgh and Barger 1911) and dissolved in deionized water. The purity of the product was determined by NMR and high-performance liquid chromatography (HPLC) analysis (Béguiristain et al. 1995). IAA, 2,4-D, and NAA were purchased from Sigma (St Louis).

\section{Plant material.}

The study was realized on A. thaliana L. (ecotype Columbia). Seedlings were germinated on solid media $\left(10 \mathrm{~g} \mathrm{l}^{-1}\right.$ Bacto agar from Difco [Detroit, MI, U.S.A.]) in BS (5 mM Mes, $1 \mathrm{mM}$ $\mathrm{CaCl}_{2}, 1 \mathrm{mM} \mathrm{KCl}$, and $5 \mathrm{mM}$ Tris, $\mathrm{pH}$ 5.8) supplemented or not with IAA, 2,4-D, NAA, or hypaphorine. Plates were maintained vertically to allow full elongation of the roots on the surface of the medium. Incubation was done at $22 \pm 2{ }^{\circ} \mathrm{C}$ in continuous white light $\left(40 \mu \mathrm{E} \mathrm{m}^{-2} \mathrm{~s}^{-1}\right)$. Root lengths of 4-day-old seedlings were scored under a binocular magnifying microscope. Root hairs strictly localized in the root hair initiation zone [zone 1 according to Heidstra and associates (1994)] were recorded with a camera (CCD-IRIS-Sony, Bioblock, Paris) on a light microscope. Lengths of the root hairs in the first millimeter from the root tip were then measured using image analysis software KappaImageBase-2.2SP2-Metreo (Kappa Optoelectronics GmbH, Gleichen, Germany). Data presented are the mean values from at least six seedlings \pm standard error (SE). Independent replicate experiments (3 to 10) were conducted for each treatment; all of them giving similar results.

For the Northern blot experiment, surface-sterilized seeds were sown on solid agar medium (Murashige-Skoog; Sigma, $1 \%$ sucrose, $1.5 \%$ agarose ) and grown vertically for 7 days at $22^{\circ} \mathrm{C}$ with a $16 \mathrm{~h}$ light period $\left(80 \mu \mathrm{E} \mathrm{m} \mathrm{m}^{-2} \mathrm{~s}^{-1}\right)$. For chemical treatment, plants were gently harvested, preincubated in BS for $1 \mathrm{~h}$, and then transferred in BS-based solutions for the times indicated. Roots were then excised and immediately frozen in liquid nitrogen.

A. thaliana L. (ecotype Columbia) suspension cells (Axelos et al. 1992) for electrical recordings were cultured at $22 \pm 2{ }^{\circ} \mathrm{C}$, under continuous white light $\left(40 \mu \mathrm{E} \mathrm{m} \mathrm{m}^{-2} \mathrm{~s}^{-1}\right)$ with rotation shaking, in one-liter round bottom flasks containing $300 \mathrm{ml}$ Gamborg culture medium, pH 5.8 (Gamborg et al. 1968). Cells were subcultured weekly by a 10-fold dilution. Experiments were conducted on 4-day-old cultures.

\section{Northern blot analysis.}

Total RNA was extracted using the Tri Reagent protocol (Sigma), electrophoresed, and transferred onto Hybond N nylon membrane (Amersham, Uppsala, Sweden) by standard procedures. A gene-specific probe for AtGST8 (GenBank accession number AJ012571), corresponding to the $3^{\prime}$ region of the cDNA, was obtained by polymerase chain reaction (PCR) (sense oligonucleotide, GCCTGATCCTGAGAA; antisense, M13 on pSPORT1 plasmid containing EST 198KT7). A genespecific probe for IAAl was obtained by nested PCR on firststrand cDNA synthesized with Oligo dT-primed Superscript II reverse transcriptase, according to the supplier's instruction (Bethesda Research Laboratories, Gaithersburg, MD, U.S.A.). Oligonucleotides were designed to amplify a 450-bp region from GenBank accession number L15448 (sense, GGAAGTCACCAATGGGCTTA; sense-nested, GATTACCC-
GGAGCACAAGAA; antisense, CAGTAGGAGCTTCGGATCCTT). Single-stranded probes were synthesized by a nonexponential $20 \mu \mathrm{l}$ PCR reaction (40 cycles) containing $2 \mathrm{ng}$ of purified cDNA insert, 0.5 to $1 \mu \mathrm{mol}[\alpha-32 \mathrm{P}]$ dATP (ICN, Orsay, France; spec. activity $3000 \mathrm{Ci} \mathrm{mol}-1,10 \mathrm{mCi} \mathrm{ml}^{-1}$ ), adapted dNTPs concentrations $(5 \mu \mathrm{M}$ dATP, $25 \mu \mathrm{M}$ each of dCTP, dGTP, and dTTP), antisense oligonucleotide at 0.5 $\mu \mathrm{Mol}$, Taq polymerase, and reaction buffer as indicated by the supplier (Qiagen, Hilden, Germany). Hybridization conditions were as described in Church and Gilbert (1984). Hybridization signals were quantified either on autoradiographs using the NIH Image program (version 1.62 software; NIH, Bethesda, MD, U.S.A.) (Fig. 4A) or with a Storm 840 PhosphorImager (Molecular Dynamics, Sunnyvale, CA, U.S.A.) (Fig. 4B). Values were corrected for loading differences as assessed by hybridization with an $18 \mathrm{~S}$ ribosomal probe.

\section{Electrophysiology.}

Impalements of root hairs and suspension cells were performed with borosilicate capillary glass (Clark GC 150F) micropipettes (resistance: 40 to $80 \mathrm{M} \Omega$ when filled with 600 $\mathrm{mM} \mathrm{KCl}$ ) as previously described (Bouteau et al. 1999; Jeannette et al. 1999). Root hair membrane potential $\left(\mathrm{V}_{\mathrm{m}}\right)$ was measured using an Axoclamp 2B amplifier (Axon Instruments, Foster City, CA, U.S.A.). Individual suspension cells were voltage-clamped, using the same amplifier designed for discontinuous single electrode voltage clamp experiments (Finkel and Redman 1985). Voltage and current were digitized with a personal computer fitted with a Digidata 1320A acquisition board (Axon Instruments). The electrometer was driven by pClamp software (pCLAMP8; Axon Instruments). Measurements on root hairs were done on the solid medium complemented with BS to avoid handling of the plantlets (Dauphin et al. 2001). Measurements on suspension cells were done in the Gamborg medium (main ions, after 4 days of culture, $9 \mathrm{mM} \mathrm{K}^{+}$and 11 $\mathrm{mM} \mathrm{NO}{ }_{3}^{-}$) as previously described (El-Maarouf et al. 2001). Experiments were performed at $22 \pm 2^{\circ} \mathrm{C}$.

\section{ACKNOWLEDGMENTS}

We wish to thank A. Azmi, H. El-Maarouf, J. M. Frachisse, Y. Matthieu, and A. M. Pennarun for stimulating discussions. We are grateful to C. Selve (Université Nancy I, France) for synthesizing the hypaphorine and to $\mathrm{H}$. Lagrange for hypaphorine HPLC analysis. This work was supported by the Ministère de l'Education Nationale (MEN) EA 3514.

\section{LITERATURE CITED}

Abel, S., Oeller, P. W., and Theologis, A. 1994. Early auxin-induced genes encode short-lived nuclear proteins. Proc. Natl. Acad. Sci. U.S.A. 91:326-30.

Axelos, M., Curie, C., Mazzolini, L., Bardet, C., and Lescure, B. 1992. A protocol for transient gene expression in Arabidopsis thaliana protoplasts isolated from suspension cultures. Plant Physiol. Biochem. 30:123-128.

Barker, S. J., and Tagu, D. 2000. The roles of auxins and cytokinins in mycorrhizal symbioses. J. Plant Growth Regul. 19:144-154.

Barker, S. J., Tagu, D., and Delp, G. 1998. Regulation of root and fungal morphogenesis in mycorrhizal symbioses. Plant Physiol. 116:12011207.

Bates, G. W., and Goldsmith, H. M. 1983. Rapid response of the plasma membrane potential in oat coleoptiles to auxin and other weak acids. Planta 159:231-237.

Béguiristain, T., Cote, R., Rubini, P., Jay-Allemand, C., Lapeyrie, F. 1995. Hypaphorine accumulation in the hyphae of the ectomycorrhizal fungus Pisolithus tinctorius. Phytochemistry 40:1089-1091.

Béguiristain, T., and Lapeyrie, F. 1997. Host plant stimulates hypaphorine accumulation in Pisolithus tinctorius hyphae during ectomycorrhizal infection while excreted fungal hypaphorine controls root hair development. New Phytol. 136:525-532.

Beyrle, H. 1995. The role of phytohormones in the function and biology 
of mycorrhizas. Pages 365-390 in: Mycorrhiza: Structure, Molecular Biology and Function. A. K. Varma and B. Hock, eds, Springer-Verlag, Berlin.

Bianchi, M. W., Roux, C., and Vartanian, N. In press. Drought regulation of GST8, encoding the Arabidopsis homologue of ParC/Nt107 glutathione transferase/peroxidase. Physiol. Plant.

Blatt M. R., and Thiel, G. 1993. $\mathrm{K}^{+}$channels of stomatal guard cells: Bimodal control of the $\mathrm{K}^{+}$inward rectifier evoked by auxin. Plant $\mathrm{J}$. 5:55-68.

Bouteau, F., Pennarun, A. M., Kurkdjian, A., Convert, M., Cornel, D., Monestiez, M., Rona, J. P., and Bousquet, U. 1999. Ion channels of young root hairs from Medicago sativa. Plant Physiol. Biochem. 37:889-898.

Brummer, B., Potrykus, I., and Parish, R. W. 1984. The roles of cell wall acidification and proton-pump stimulation in auxin-induced growth: Studies using monensin. Planta 162:345-352.

Church, G. M., and Gilbert, W. 1984. Genomic sequencing. Proc. Natl. Acad. Sci. U.S.A. 81:1991-1995.

Cleland, R. E., Prins, H. B., Harper, J. R., and Higinbotham, N. 1977. Rapid hormone-induced hyperpolarization of the oat coleoptile transmembrane potential. Plant Physiol. 59:395-397.

Cullimore, J. V., Ranjeva, R., and Bono, J. J. 2001. Perception of lipochitoologosaccharidic Nod factors in legumes. Trends Plant Sci. 6:24-30.

Dauphin, A., El-Maarouf, H., Vienney, N., Rona, J. P., and Bouteau, F. 2001. Effect of desiccation on potassium and anion currents from young root hairs. Implication on tip growth. Physiol. Plant 113:79-84.

Dénarié, J., and Cullimore, J. 1993. Lipo-ologosaccharide nodulation factors: A new class of signaling molecules mediating recognition and morphogenesis. Cell 74:951-954.

Ditengou, F. A., and Lapeyrie, F. 2000. Hypaphorine from the ectomycorrhizal fungus Pisolithus tinctorius counteracts activities of indole3 -acetic acid and ethylene but not synthetic auxins in Eucalypt seedlings. Mol. Plant-Microbe Interact. 13:151-158.

Ditengou, F. A., Béguiristain, T, and Lapeyrie, F. 2000. Root hair elongation is inhibited by hypaphorine, the indole alkaloid from ectomycorrhizal fungus Pisolithus tinctorius, and restored by indole-3-acetic acid. Planta 211:722-728.

Edwards, R., Dixon, D. P., and Walbot, V. 2000. Plant glutathione-Stransferases: Enzymes with multiple functions in sickness and in health. Trends Plant Sci. 5:193-198.

Ehrhardt, D. W., Atkinson, E. M., and Long, S. R. 1992. Depolarization of alfalfa root hair membrane potential by Rhizobium meliloti Nod-factors. Science 256:998-1000.

El-Maarouf, H., Barny, M. A., Rona, J. P., and Bouteau, F. 2001. Harpin, a hypersensitive response elicitor from Erwinia amylovora regulates ion channel activities in Arabidopsis thaliana suspension cells. FEBS (Fed. Eur. Biochem. Soc.) Lett. 497:82-84

Felle, H., Brummer, B., Bertl, A., and Parish, R. W. 1986. Indole-3-acetic acid and fusicoccin cause cytosolic acidification of corn coleoptile cells. Proc. Natl. Acad. Sci. U.S.A. 83:8892-8995.

Felle, H., Peters, W., and Palme, K. 1991. The electrical response of maize to auxins. Biochim. Biophys. Acta 1064:199-204.

Felle, H. H., Kondorosi, E., Kondorosi, A., and Schultze, M. 1998. The role of ion fluxes in Nod-factor signaling in Medicago sativa. Plant J. 13:455-463.

Finkel, A. S., and Redman, S. J. 1985. Optimal voltage clamping with single electrode. Pages 95-120 in: Voltage and Patch Clamping with Microelectrodes. T. G. Smith, Jr., H. Locar, S. J. Redman, P. W. Gage, eds. American Physiological Society, Bethesda, MD, U.S.A.

Gamborg, O. L., Miller, R. A., and Ojima, K. 1968. Nutrient requirement of suspension cultures of soybean root cells. Exp. Cell Res. 50:151.

Ghellis, T., Dellis, O., Jeannette, E., Bardat, F., Cornel, D., Miginiac, E., Rona, J. P., and Sotta, B. 2000. Abscisic acid-specific expression of $R A B 18$ involves activation of anion channels in Arabidopsis thaliana suspension cells. FEBS (Fed. Eur. Biochem. Soc.) Lett. 474:43-47.

Gay, G., Normand, L., Marmeisse, R., Sotta, B., and Debaud, J. C. 1994. Auxin overproducer mutants of Hebeloma cylindrosporum romagnesi have increased mycorrhizal activity. New Phytol. 128:645-657.

Gogala, N. 1991. Regulation of mycorrhizal infection by hormonal factors produced by hosts and fungi. Experientia 47:331-340.

Gough, C., Vasse, J., Galera, C., Webster, G., Cocking, E., and Dénarié, J. 1997. Interactions between bacterial diazotrophs and nonlegume dicots: Arabidopsis thaliana as a model plant. Plant Soil 194:123-130.

Hahn, M., and Mendgen, K. 2001. Signal and nutrient exchange at biotrophic plant-fungus interfaces. Curr. Opin. Plant Biol. 4:322-327.
Hedrich, R., Busch, H., and Raschke, K. 1990. $\mathrm{Ca}^{2+}$ - and nucleotide-dependent regulation of voltage-dependent anion channels in the plasma membrane of guard cells. EMBO (Eur. Mol. Biol. Organ.) J. 9:3889-92.

Heidstra, R., Geurts, R., Franssen, H., Spaink, H. P., van Kammen, A., and Bisseling, T. 1994. Root hair deformation activity of nodulation factors and their fate on Vicia sativa. Plant Physiol. 105:787-797.

Jeannette, E., Rona, J. P., Bardat, F., Cornel, D., Sotta, B., and Miginiac, E. 1999. Induction of $R A B 18$ gene expression and activation of $\mathrm{K}^{+}$ outward rectifying channels depend on extracellular perception of ABA in Arabidopsis thaliana suspension cells. Plant J. 18:13-22.

Kaldorf, M., and Ludwig-Müller, J. 2000. AM fungi might affect the root morphology of maize by increasing indole-3-acid biosynthesis. Physiol. Plant 109:58-67.

Keller, C. P., and Van Volkenburgh, E. 1996. The electrical response of Avena coleoptile cortex to auxins. Planta 198:404-412.

Keller, C. P., and Van Volkenburgh, E. 1998. Evidence that auxin-induced growth of tobacco leaf tissues does not involve cell wall acidification. Plant Physiol. 118:557-564.

Kurkdjian, A. 1995. Role of the differentiation of root epidermal cells in Nod-factor (from Rhizobium meliloti) induced root hair depolarization of Medicago sativa. Plant Physiol. 107:783-790.

Kurkdjian, A., Bouteau, F., Pennarun, A. M., Convert, M., Cornel, D., Rona, J. P., and Bousquet, U. 2000. Ion currents involved in early Nod-factor response in Medicago sativa root hairs: A discontinuous single-electrode voltage clamp study. Plant J. 22:9-18.

Laurans, F., Pepin, R., and Gay, G. 2001. Fungal auxin overproduction affects the anatomy of Hebloma cylibdrosporum-Pinus pinaster ectomycorrhiza. Tree Physiol. 21:533-540.

Marrs, K. 1996. The functions and regulation of glutathione-S-transferases in plants. Annu. Rev. Plant Physiol. Plant Mol Biol. 47:127158.

Marten, I., Loshe, G., and Hedrich, R. 1991. Plant growth hormones control voltage-dependent activity of anion channels in plasma membrane of guard cells. Nature 353:758-762.

Martin, F., Lapeyrie, F., and Tagu, D. 1997. Altered gene expression during ectomycorrhizal development. Pages 223-242 in: The Mycota. Vol. V. A. G. Carroll, P. Tudzynski, eds. Springer-Verlag, Berlin.

Nehls, U., Béguiristain, T., Ditengou, F., Lapeyrie, F., and Martin, F 1998. The expression of a symbiosis-regulated gene in eucalypt roots is regulated by auxins and hypaphorine, the tryptophan betaine of the ectomycorrhizal basidiomycete Pisolithus tinctorius. Planta 207:296302.

Romburgh, P. V., and Barger, G. 1911. Preparation of the betaine of tryptophan and its identity with the alkaloid hypaphorine. J. Am. Chem. Soc. 99:2068-2070.

Rück, A., Palme, K., Venis, M. A., Napier, A. M, and Felle, H. 1993. Patch-clamp analysis establishes a role for an auxin binding protein in the auxin stimulation of plasma membrane current in Zea mays protoplasts. Plant J. 4:41-46.

Santoni, V., Vansuyt, G., and Rossignol, M. 1990. Differential auxin sensitivity of proton translocation by plasma membrane $\mathrm{H}^{+}$-ATPase from tobacco leaves. Plant Sci. 68:33-38.

Schaller, A., and Frasson, D. 2001. Induction of wound response gene expression in tomato leaves by ionophores. Planta 212:431-435.

Schroeder, J. I., Keller, B. U. 1992. Two types of anion channel currents in guard cells with distinct voltage regulation. Proc. Natl. Acad. Sci. U.S.A. 89:5025-5029

Tretyn, A., Wagner, G., and Felle, H. 1991. Signal transduction in Sinapis alba root hairs: Auxins as external messengers. J. Plant Physiol. 139:187-193.

van Rhijn, P., Fang, Y., Galili, S., Shaul, O., Atzmon, A., Wininger, S., Eshed, Y., Lum, M., Li, Y., To, V., Fujishige, N., Kapulnik, Y., and Hirsch, A. M. 1997. Expression of early nodulin genes in alfalfa mycorrhizae indicates that signal transduction pathways used in forming arbuscular mycorrhizae and Rhizobium-induced nodules may be conserved. Proc. Natl. Acad. Sci. U.S.A. 94:5647-5472.

Yuasa, K., Takahashi, K., and Katou, K. 1998. Calcium chelator and channel blockers suppress the IAA-induced membrane hyperpolarization without inhibiting the following growth promotion in hypocotyls sections of Vigna unguiculata under xylem perfusion. Plant Cell Physiol. 39:978-986.

Zimmermann, S., Thomine, S., Guern, J., and Barbier-Brygoo, H. 1994. An anion current at the plasma membrane of tobacco protoplasts shows ATP-dependent voltage regulation and is modulated by auxin. Plant J. 6:707-716. 